\title{
EL DERECHO DE COARTACIÓN DEL ESCLAVO EN LA AMÉRICA ESPAÑOLA
}

POR

MANUEL LUCENA SALMORAL

Universidad de Alcalá

\begin{abstract}
La coartación o derecho del esclavo a comprar su libertad pagando su precio al amo mediante un sistema de abonos periódicos fue un derecho consuetudinario en la América española y generó el mayor numero de manumisiones, permitiendo la aparición de una población negra libre que fue característica de estas colonias. Funcionó usualmente desde mediados del siglo XVIII hasta la abolición y originó una serie de problemas jurídicos en relación con la posible venta de dicho esclavo a otro amo por el pago de alcabala (si debía pagarse de la parte coartada), así como su incidencia en el hijo de una esclava coartada, ya que la condición de esclavo la heredaba de su madre (libre en parte). Las soluciones que se dieron a estos casos son objeto de este trabajo.
\end{abstract}

Coartación fue sinónimo de manumisión de un esclavo en la América española $^{1}$, pero a partir de 1768 tuvo otro significado diferente como el procedimiento de compra de libertad del esclavo mediante el pago de sumas periódicas al amo hasta saldar todo su valor. Un esclavo coartado había así autoamortizado parte de su precio (el 20,30, 50 ó 90\% del total), mientras que el que no lo era se llamaba

\section{SIGLAS UTILIZADAS:}

A.H.N.: Archivo Histórico Nacional, Madrid

A.G.I.: Archivo General de Indias, Sevilla

Brit. Libr.: Brithis Library, Londres

Bibl. Nal.: Bilbioteca Nacional, Madrid

Bibl. Pal: Biblioteca de Palacio Real, Madrid.

1 Entendida como tal manumisión del esclavo por entrega de su valor total al amo, o por algún otro mecanismo, figuró en la documentación esclavista de la América española. Así, por ejemplo, el Gobernador interino de La Habana Pedro Alonso publicó un bando en septiembre de 1760 otorgando la «coartación» al esclavo que delatara haber sido carimbado fraudulentamente. Olga PORTUONDO ZÚÑIGA, «Marcas de carimbar esclavos en el siglo XVIII», Revista Revolución y Cultura, Santiago, 1982, febrero, pp. 65-66. 
«entero», porque debía al amo todo su costo. A partir de entonces, y hasta fines de la esclavitud, los esclavos se vendieron como coartados o enteros.

La coartación fue el mecanismo que liberó mayor número de esclavos en Hispanoamérica. En realidad fue el único efectivo, ya que los restantes eran poco seguros: La huida del amo, incluso con su posible secuela del apalencamiento, conllevaba siempre el peligro de ser capturado y restituido a la esclavitud después de sufrir terribles castigos; la denuncia por sevicia del amo originaba largos e inciertos pleitos que terminaban en el mejor de los casos con el traslado a otro dueño; y la manumisión por «gentileza» del amo, como se decía entonces (significado antiguo de la palabra coartación), era muy poco usual, contra lo que algunos benévolos historiadores piensan. Para esto último había que dar con un amo que tuviera conciencia de la explotación inhumana que realizaba (cosa poco usual entre quienes vivían de la esclavitud), y que estuviera a punto de morirse (momento en el que al parecer se acentuaban los escrúpulos morales) y finalmente a que sus herederos estuvieran dispuestos a respetar la voluntad del moribundo, totalmente contraria a sus intereses, lo que era aún más raro, si cabe. En el siglo XIX y a partir de 1817 funcionaron otros mecanismos de liberación de esclavos en las islas antillanas, como fueron la emancipación ${ }^{2}$, la aplicación de las leyes de Libertad de Vientres de Moret ${ }^{3}$, la abolición de la esclavitud en Puerto Rico decretada por la República ${ }^{4}$ y finalmente la misma abolición ordenada en

2 Los emancipados aparecieron a partir del Tratado de supresión de la Trata en 1817 y eran los esclavos transportados a las colonias hispanoamericanas que eran capturados por los cruceros de guerra o eran descubiertos por las autoridades insulares en el momento de ser desembarcados, convirtiéndose automáticamente en libres por el artículo VII de dicho Tratado. Vide Inés RoLDAN DE MONTAUD, «Origen, evolución y supresión del grupo de negros «emancipados» en Cuba (1817-1870)», Revista de Indias, núms. 169-170, Madrid, 1982, pp. 559-641.

3 Vide el Decreto de abolición de la esclavitud en la forma y bajo las reglas que se expresan (Ley Moret o de la libertad de vientres) dada en San Ildefonso el 4 de julio de 1870. A.H.N., Ultramar, 5111/20; Marcelo MARTINEZ AlCubilla, Diccionario de la Administración Española, Madrid, Administración Arco de Santa María, 1993, t. V, pp. 274-275; El proceso abolicionista en Puerto Rico: Documentos para su estudio, San Juan, Centro de Investigaciones Históricas, Universidad de Puerto Rico e Instituto de Cultura Puertorriqueña, 1974-19782, vol. II, pp. 131-133; Enrique Perez-Cisneros, La abolición de la esclavitud en Cuba, San José de Costa Rica, Litografía e Imprenta Lil, S.A., 1987, 177 pp. 128-132; Hortensia PICHARDO, Documentos para la Historia de Cuba, La Habana, Editorial de Ciencias Sociales, 1977, t. I, pp. 383-386; Concepción NAVARRo AzcuE, La abolición de la esclavitud negra en la legislación española, 1870-1886, Madrid, Ediciones Cultura Hispánica, 1987, pp. 249-251.

4 Vide la Ley de abolición de la esclavitud en Puerto Rico dada por la I República Española en Madrid el 22 de marzo de 1873. Una copia impresa de la Gaceta de Madrid del 26 de marzo de 1873 en que se contiene la ley se encuentra en A.H.N., Ultramar, 5111/20, donde existe así mismo una copia hológrafa firmada por Estanislao Figueras al Ministro de Ultramar, y el telegrama cursado por el Ministerio de Ultramar al Gobierno de Puerto Rico. En A.H.N., Ultramar, 5111/23 existe otro ejemplar de la ley impresa en Puerto Rico por González, Impresor de Gobierno, en 1873, que tienen numerosos errores de imprenta corregidos, tales como denominar «libertados» a los libertos,

R. I., $1999, \mathrm{n}^{\circ} 216$ 
Cuba por la monarquía restaurada ${ }^{5}$, pero no tuvieron aplicación en la América continental española, cuyo mejor instrumento de ahorramiento fue la coartación, como hemos dicho.

La coartación podríamos definirla mejor como el derecho de un esclavo para comprar a plazos su libertad, pagando periódicamente a su dueño diversas cantidades, hasta completar totalmente el precio por el que había sido adquirido. Las cantidades se iban anotando en su título de compra. Cuando llegaba a saldar todo el precio se le daba automáticamente la carta de ahorría, pasando a ser libre. El procedimiento presuponía dos principios que estaban en contra de los fundamentos de la institución esclavista, como eran que la esclavitud estaba basada en una mera relación mercantil o de compra (que cesaba automáticamente cuando se restituía su valor), y que el esclavo podía poseer un pequeño peculio en propiedad, con el que podría ir saldando progresivamente su costo como mercancía.

Lo primero (que la esclavitud estaba fundamentada en una relación de compra) era muy grave, pues derribaba todo el andamiaje jurídico que había fundamentado la esclavitud (la de los esclavos habidos en justa guerra, por indigencia o por ser hijos de esclava) y suponía restablecer el principio de que dicha esclavitud, tal como señalaran las Partidas, no estaba en la naturaleza humana, sino en las circunstancias históricas (los pecados de los hombres, que había acabado con la primigenia «Edad de Oro» de la creación divina, cuando todos los seres humanos fueron libres, ya que Dios no había creado esclavos), por lo que el esclavo tenía naturalmente derecho a volver a su libertad natural, verdadera aspiración de todo ser humano: «Aman e cobdician naturalmente todas las criaturas del mundo la libertad, cuanto más los hombres que han entendimiento sobre todas las otras, e mayormente en aquellos que son de noble corazón» ${ }^{6}$. La única razón por la que un hombre había perdido su libertad era evidentemente haber sido vendido a un amo, de lo que derivaba que pudiera volver a ser libre, si lograba restituirle su precio. El esclavo no lo era por naturaleza, en definitiva, sino por una circunstancia del sistema capitalista; haber sido vendido. Sobraban por consiguiente todas las disquisiciones jurídicas que habían intentado camuflar esta realidad. Y esto, como es natural, no podía reconocerse por ley. De aquí que la libertad del esclavo

\footnotetext{
un articulado equivocado, etc. Otras copias de la ley en la prensa de la época, como por ejemplo en El Imparcial del domingo 23 de marzo de 1873, p. 1.

5 Vide la Ley de supresión de la esclavitud en Cuba dada en Madrid por Alfonso XII el 13 de febrero de 1880. Gaceta de Madrid, 18 de febrero de 1880; PÉrEZ-CisNeros [3], pp. 137-143; PICHARDo [3], t. I,pp. 414-418; también los periódicos de la época, como El Tiempo, Madrid, 6 de diciembre de 1779 , p. 2 , col. 2 y 3 , que publicó el dictamen de la Comisión sobre abolición de la esclavitud en Cuba, leído en el Senado el 5 de diciembre de 1779.

6 Vide sobre este problema Manuel LuCENA SALMORAL, «La esclavitud americana y Las Partidas de Alfonso X», Revista Indagación, Alcalá de Henares, Servicio de Publicaciones de la Universidad, 1995, pp. 33-44.
} 
por compra de si mismo funcionara como un derecho consuetudinario hasta el siglo XVIII, cuando fue necesaria regularla porque era una práctica común.

El reconocimiento de que el esclavo pudiera poseer un peculio era otra bomba lanzada contra la línea de flotación de la institución esclavista, fundamentada en el principio de que todo lo que producía un esclavo era propiedad de su amo (cosa que defendieron además con ardor muchos propietarios de esclavos españoles en el siglo XVIII). En Hispanoamérica estaba plenamente admitida la contradicción de que el esclavo no tenía derecho a ninguna propiedad y tenía a la vez derecho a poseer un peculio. Cuando el Gobernador O'Reilly legalizó el 27 de octubre de 1769 el Código Negro francés en la Luisiana española ${ }^{7}$ no puso ninguna objeción a su artículo 22, que señalaba: «Declaro que nada pueden poseer los esclavos que no sea del dominio de sus amos, y cuanto adquieran por su industria, o por la deliberación de otras personas, o cualquier motivo, o título que sea, lo que adquieran será de plena propiedad de sus amos» ${ }^{8}$. Resultaba así que el peculio solo podía entenderse como el derecho de un esclavo para hurtar a su amo pequeñas sumas, y con su consentimiento, lo que lógicamente no pudo regularse en justicia. No se dió como ley, pero dicho peculio o derecho al hurto del esclavo funcionó como otro derecho consuetudinario de la América española, sin que planteara muchos problemas, salvo casos aislados 9 .

$\mathrm{Ni}$ el derecho de un esclavo a comprar su libertad pagando su precio de compra al amo, ni el derecho a tener peculio fueron regulados, pero algunos historiadores han caído en la trampa de buscar denodadamente tales leyes. No vamos a citarlos, bastándonos simplemente con señalar que un jurista como Mansini ${ }^{10}$ consideró que el derecho del esclavo para comprar su libertad y aún el de la coartación lo dio el Emperador en el año 1526. Masini se basó en una afirmación similar hecha por el P. Bayle, quien aseguró que Felipe V estableció el derecho de que el amo admitiera cantidades del esclavo a cuenta de su rescate, basado en

7 Juan José ANDREU OCARIZ, Movimientos rebeldes de los esclavos durante el dominio español en Louisiana, Zaragoza, Universidad de Zaragoza, 1977, p. 25.

8 Una copia de este Código, traducida al español, se encuentra en Bibl. Pal., Mss. de América, núm. 277, pp. 13-21v.

9 En la representación de los dueños de minas de Barbacoas a su Cabildo el 27 de octubre de 1792 señalaron con enorme lógica lo irregular de que los esclavos autocomprasen su libertad: «pues debiendo ser todo lo que adquiere el esclavo para el amo, no cediendo éstos a aquellos más de lo necesario para sus alimentos, es claro que lo consignado es del amo y no puede servir de precio a la libertad, mayormente cuando por derecho, sin voluntad del amo, no se le debe conferir la libertad, aunque haya un extraño que por piedad quiera libertarlo, y cuando además de todo esto aquí concurre la presunción, no como quiera, sino la presunción que el derecho llama violenta, de que aquello es robado». Archivo Histórico Nacional del Ecuador, Reales Cédulas, t. XIII, flos 220-222.

10 José Luis MASINI, Régimen jurídico de la esclavitud negra en Hispanoamérica hasta 1810, Mendoza, s.d., p. 24.

R. I., $1999, \mathrm{n}^{\circ} 216$ 
la carta Imperial de $1526^{11}$, pero resulta que Bayle interpretó equívocamente dicha carta, que dio efectivamente Carlos V en Granada el 9 de noviembre de 1526, consultando al Gobernador de la Nueva España sobre la conveniencia de que «para que los negros que se pasan a esas partes se asegurasen, y no se alzasen y se ausentasen, y se animasen a trabajar y servir a sus dueños con más voluntad, demás de casarlos, sería [conveniente] que sirviendo cierto tiempo, y dando cada uno a su dueño hasta veinte marcos de oro por lo menos, y dende arriba lo que a vosotros pareciere, según la calidad y condición y edad de cada uno, y a este respecto subiendo o bajando en el tiempo y precio [a] sus mujeres e hijos, de los que fueren casados, quedasen libres y tuviesen de ello certinidad»12. No fue ninguna ley, sino una simple consulta a sobre la conveniencia de tomar tal medida. Zorita nos dijo que el monarca hizo la misma sugerencia a las Audiencias indianas mediante una cédula dada en Fuensalida el 26 de octubre de $1541^{13}$, pero no hemos encontrado ninguna respuesta a esta consulta, que desgraciadamente no se hizo, no constando por consiguiente como ley. Desgraciadamente, decimos, pues habría significado nada menos que el establecimiento de la esclavitud temporal en América española, en vez de la vitalicia. Bayle cogió el rábano por las hojas al hacer su aseveración y sus seguidores han seguido transmitiendo el error sin verificar sus fuentes.

Aparte de los dos principios señalados del derecho del esclavo a comprar su libertad y de poseer un peculio, la coartación añadió otro más, como fue presuponer que el precio del esclavo era muy alto en relación con el peculio que podía ganar éste trabajando en las fiestas y en sus ratos libres (frecuentemente sus horas de sueño), lo que determinaba la necesidad de permitirle adquirir su libertad entregando pequeñas sumas a cuenta. Era, en definitiva, una compra de libertad a plazos, aunque sin intereses. Lo usual era que el esclavo fuera pagando partes de su valor hasta que saldaba la mayor parte del mismo, recurriendo entonces a los

11 Bayle escribió (y Masini lo copió textualmente): «Felipe V (21 de junio 1708) obliga al amo a admitir del esclavo cantidades a cuenta del rescate, que se tasaban en 20 marcos, y cita entonces la carta imperial de 1526 añadiendo «y desde allí data la opción de comprar la libertad». Constantino BAYLE, S.J., España en Indias, Madrid, Biblioteca del Imperio, Editora Nacional, 1942, tercera edición, p. 360.

12 A.G.I., Indiferente, 421, lib. 11, flo. 300; Manuel AyAlA, Diccionario de Gobierno y Legislación de Indias, t. 99, flo. 88, núm. 95; Vasco de PugA: Provisiones, cédulas, instrucciones de S.M...., México, 1563, Reimpresión facsimilar en Madrid, 1945, t.I, p. 32; Richard KonETZKE: Colección de documentos para la historia de la formación social de Hispanoamérica, 1493-1810, Madrid, C.S.I.C., 1953-1962, vol. I, p. 88. En Encinas figura la misma carta, pero datada en 1528, es decir, dos años después, Diego de Encinas, Provisiones, cédulas, capítulos de ordenanzas, instrucciones y cartas libradas..., Madrid, Imprenta Real, 1596, Reimpresión facsimilar en Madrid, 1946, t. IV, p. 398 y en Zorita tenemos una cédula dada en Fuensalida el 26 de octubre de 1541 en que se somete el asunto a la consideración de las Audiencias, Alonso ZORITA, Leyes y ordenanzas reales de las Indias del mar Océano..., 1574, México, Secretaria de Hacienda y Crédito Público, 1984, p. 125.

13 ZORITA [12], p. 125. 
parientes o amigos para que le prestaran lo que le faltaba; 25, 50 ó 100 pesos. A cambio de este dinero ofrecía a menudo contraprestaciones, como el compromiso de trabajar luego gratis para los prestamistas durante algún tiempo, cuando fuera hombre libre o ahorrado.

La coartación, la verdadera o por compra a plazos, tampoco se estableció mediante una ley y sólo apareció en la América española tardíamente, durante el siglo XVIII, semejándose en esto al derecho de coartación total y al del peculio, que le servían de fundamento. Tal como anotara sagazmente Alan Watson la «coartación resulted from practice, not from official intervention of royal legislation ${ }^{14}$. La primera vez que la encontramos en el ordenamiento jurídico esclavista es en una real cédula dirigida al Gobernador de la Habana el 21 de junio de $1768^{15}$ y relacionada con los problemas que había originado el cobro del derecho de alcabala aplicado a la venta de esclavos. En dicha cédula se habla de «la venta voluntaria o involuntaria de parte de los amos de los negros, mulatos, esclavos coartados», aludiendo a algo que funcionaba normalmente, lo que ratifican otros documentos posteriores de $1769^{16}$ y $1788^{17}$. La coartación fue por tanto otro derecho consuetudinario, firmemente asentado en Hispanoamérica durante la segunda mitad del siglo XVIII.

\section{REGULACION DE MANUMISIONES, INCLUIDAS LAS DE COARTACION, Y COBROS DE ALCABALA}

En el documento citado de 1768 se planteaba lo injusto de que tuvieran que pagar el impuesto de alcabala los esclavos que compraban su libertad o los dueños que eran obligados a vender sus esclavos (usualmente por haber cometido sevicia con ellos). El asunto lo promovió el Gobernador de Cuba, isla en la que acaba de introducirse dicho impuesto. La alcabala, y mejor su subida, como han señalado Kuethe e Inglis, fue el remedio milagroso para recaudar fondos con los cuales se pudiera organizar la planta defensiva de Cuba después de la ocupación inglesa. Una junta de ministros celebrada en marzo de 1764 bajo la dirección de Esquilache acordó incrementarla en Cuba del 2 al 4\%, elevando 2 pesos el precio

\footnotetext{
14 Alan Watson, Slave Law in the Americas, Georgia, The University of Georgia Press, Athens and London, 1989, p. 51.

15 R.C. al Gobernador de La Habana aclarando lo regulado para el cobro de alcabala por la venta de esclavos y manumisión o coartación de los mismos, dada en Aranjuez el 21 de junio de 1768. A.G.I., Santo Domingo, 890, lib. 58, flo. 330; KONETZKE [12], vol. III, t. I, pp. 337-340.

16 Real Cédula al Gobernador de la Habana mandando aplicar a los esclavos coartados el mismo método de cobro de alcabala que a los enteros, dada en San Ildefonso el 27 de septiembre de 1769. A.G.I., Santo Domingo, 891, flo. 414v; KonETZKE [12], vol. III, t. I, pp. 360-361.

17 Resolución del Consejo de Indias sobre que la coartación de la madre no afecta al hijo de la esclava, dada en Madrid el 5 de diciembre de 1788. A.G.I., Audiencia de Santo Domingo, 1142; KONETZKE [12], vol.III, t. II, pp. 631-635.
}

R. I., 1999, n. $^{\circ} 216$ 
del barril de aguardiente y un real el barril de zambumbia (guarapo). Esquilache promulgó la subida mediante real orden de 25 de abril de 1764, que llegó en junio a La Habana y encomendó al conde de Ricla el trabajo de explicar a los habaneros los beneficios que podrían derivarse para la isla con ello (las facilidades comerciales conocidas $)^{18}$. La alcabala subió luego al $6 \%$ y, según los autores citados «From 1765 onwards, it occupied the premier position among Cuban taxes, easily representing 40 to 50 per cent of all monies generated on the island» ${ }^{19}$.

Pero dejemos la alcabala, que aquí nos interesa únicamente como agente detonante que sacó a la luz los problemas de las manumisiones y las coartaciones. El Gobernador de Cuba cursó una carta al monarca el 29 de julio de 1766 solicitando aclaraciones sobre el cobro de dicho impuesto en algunos casos dudosos, pues había dispuesto, asesorado por los abogados, que los dueños pagaran alcabala de las ventas de esclavos realizadas por su voluntad o por un apremio de pago, o por ambas cosas, pero que cuando la venta fuera forzosa y tuviera que hacerla el propietario sin desearlo (bien al propio esclavo para su manumisión o a otro dueño) debería pagarla el esclavo que se liberaba o el dueño que lo compraba. Aparte del problema del pago vemos que estaba ya firmemente asentada la idea de que el amo tenía de conceder la manumision al esclavo que le abonaba su precio.

El monarca contestó al Gobernador de Cuba el 19 de noviembre de 1766 ordenándole afianzar el producto de las ventas efectuadas, en espera de la resolución real, y remitir al Consejo los autos obrados sobre el particular. El Gobernador replicó el 30 de septiembre de 1767 indicando que la resolución la había tomado conforme al uso y costumbre en el traspaso de esclavos y que los informes de los abogados asesores y los juicios realizados sobre tales asuntos habían sido verbales «por dar pronta expedición a la administración de justicia», lo que le impedía expedir los autos requeridos.

El Consejo de Indias pidió entonces informes a la Contaduría General sobre lo que se había hecho hasta entonces en México y Perú, donde todas las ventas y contratos de esclavos se hacían mediante escritura ante escribano o juez territorial, enviándose relaciones mensuales al recaudador de la alcabala de las ventas efectuadas para cobrar los derechos de alcabala al vendedor. En ambos virreinatos estaba establecido que la alcabala de los esclavos que se vendían por mandato de la justicia (por vejación o malos tratos de los dueños) la pagaran sus propietarios «en pena de haber faltado a la humanidad y racionales modos que están obligados a usar con ellos», sin poder alterar el precio por el que los adquirieron; que igualmente pagaban la alcabala de la venta los propietarios que vendían sus esclavos por su voluntad, sin poder alterar tampoco su precio, pero que cuando el

18 Allan J. Kuethe y G. Douglas INGLIS, «Absolutism and enlightened reform: Charles III, the establishment of the Alcabala, and commercial reorganization in Cuba», Past and Present, núm. 109, november, Oxford, 1985, pp. 128-129.

19 Ibidem, p. 142. 
esclavo se comportaba mal, con objeto de obligar a su amo a venderle, entonces se incrementaba su precio con el valor de la alcabala, considerándose un castigo adecuado a su mala actitud, ya que el aumento de valor restringía las facilidades de que se liberase.

El informe señalaba que cuando los esclavos entregaban a sus señores el importe de su valor, adquirido lícitamente por medios honestos para manumitirse «son obligados los expresados dueños a otorgarles llana y jurídicamente la carta de libertad, y los títulos en cuya virtud los poseían, quedando cancelados y anotados en sus respectivos lugares, sin que les sea facultativo en este caso pedir más precio, ni recibir otra cosa, que la cantidad que exhibieron al tiempo de su adquisición, aunque aleguen que les han enseñado algunos oficios o habilidades extraordinarias, porque todo se sacrifica a beneficio de la libertad, en que siempre, o las más veces interesa el público, cuya utilidad prepondera a la privada del particular, y en este caso no se contribuye cosa alguna por razón de la alcabala, pues no la hay, cuando el esclavo adquiere por los insinuados medios, o por pura liberalidad de su dueño, en reconocimiento de sus buenos servicios, la libertad, como se halla declarado terminantemente en los mismos recudimientos».

Quedaba así claro:

1.- Que todo esclavo tenía derecho a manumitirse pagando a su dueño el precio que había pagado al comprarlo.

2.- Que el amo tenía la obligación de entregarle entonces automáticamente la carta de libertad.

3.- Que en el dueño no podía aumentar dicho precio alegando haberle enseñado oficios que valorizaban su precio inicial.

4.- Que en caso de manumisión no había que pagar alcabala alguna.

5.- Que tampoco se pagaba alcabala si el amo manumitía a su esclavo por generosidad, sin que le abonara este último ninguna suma.

Hasta aquí se utilizaba la palabra «coartación» como sinónima de manumisión, pero empezó también a aludir a la misma palabra en su sentido de compra de libertad a plazos, que será la usual a partir de entonces (1768). La orden real señaló que «cuando el esclavo entrega a su amo parte del precio que le costó, con el fin de que, rebajado de su valor principal, quede éste más moderado, y él en mayor aptitud de conseguir su libertad, se anota al instrumento que sirve de título, para que conste en todo evento», lo que confirmaba que era un derecho consuetudinario (no se aludió a ninguna ley), estipulando que las sumas o cantidades entregadas a cuenta del valor total debían anotarse en su título de propiedad.

Cuando el esclavo hubiera pagado parte de su precio mediante coartaciones y se vendiera a otro amo, bien por voluntad del dueño o del propio esclavo, había que deducir de su precio el valor de lo coartado, siendo el resto su precio de 
venta. La alcabala se pagaba entonces «únicamente de la cantidad a que queda reducido su valor, también en obsequio de la libertad».

Toda esta normativa se le envió al Gobernador de Cuba por real cédula de 21 de junio de 1768 para su implantación en la Isla ${ }^{20}$.

\section{LOS ESCLAVOS COARTADOS PAGARIAN LA ALCABALA Y NO SE TRASPASARIAN DE DUEÑO SIN EL CONSENTIMIENTO DE SU AMO}

Pero el Gobernador de Cuba don José María Bucareli escribió nuevamente al monarca el 6 de octubre de 1768, acusando recibo de la cédula de 21 de junio del mismo año sobre la exención de alcabala para los esclavos coartados, y solicitando que se diera una norma general para que no se alterase el precio de venta de los esclavos en función de que el amo quisiera hacerlo por su interés o por estar obligado a causa de haberle dado malos tratos. Pidió además información sobre la posibilidad de que los amos modificaran el precio de venta de sus esclavos en caso de tratarse de esclavos enteros o coartados. (Vemos así que el uso antiguo de la palabra «coartación» como sinónima de manumisión se presta ya a confusiones y hay que sustituirla por las de «enteros», quedando reservada «coartación» para compra a plazos). Bucareli argumentaba que el sostenimiento del precio inicial de un esclavo perjudicaba a los propietarios y favorecía a los esclavos, ya que muchos bozales adquirían destreza en «la construcción del azúcar, o al manejo y temple de los tachos, en las estancias a la quema del cazabe, en los pueblos a la fábrica de casas, o a otras ocupaciones», llegando a valer 500 ó 600 pesos. No le parecía justo que sus dueños tuvieran que venderlos por lo que les costó, pues como dichos esclavos adquirían pronto el dinero necesario para emanciparse, perjudicaban a sus propietarios y a la agricultura de la Isla.

Tampoco le parecía justo que los esclavos que se comportaban mal se vendieran por el mismo precio que habían costado, pues lo consideraba un agravio para los demás. En su opinión debían ser castigados, cargándoles el valor de la alcabala al de su precio, lo que serviría para escarmentarlos. La situación usual en Cuba era la contraria; los amos vendían estos esclavos levantiscos más baratos, para quitárselos de encima, lo que daba la impresión de que se premiaba el mal comportamiento.

El Consejo de Indias consultó el problema con la Contaduría General y finalmente dictaminó que los esclavos coartados debían regirse por la misma normativa que los enteros; que los coartados no podían cambiar de amo sin la voluntad de sus dueños (excepto los casos previstos en Derecho), y que cuando se

\footnotetext{
20 A.G.I., Santo Domingo, 890, lib. 58, flo. 330; KonETZKE [12], vol. III, t. I, p. 337-340.
} 
hiciera su traspaso a otro dueño, éste, como comprador, pagaría la alcabala con arreglo a su precio ${ }^{21}$.

La resolución del Consejo fue asumida por la Corona y trasladada al Gobernador cubano. No se aceptaron así las artimañas para subir el precio de los esclavos, que siguieron vendiéndose por su precio inicial de compra, y pudiendo manumitirse pagándolo de una vez (como «enteros») o mediante coartación.

Pero las cosas no quedaron aquí. El 26 de febrero de 1773 el Gobernador de Cuba Marqués de la Torre presentó al monarca unos «dubios» sobre el problema, fruto de una representación hecha por la Ciudad (su Cabildo) y su Síndico Personero a propósito de dos cédulas anteriores de 24 de junio de 1768 y 27 de septiembre de 1769, así como del reglamento que había impuesto recientemente la Contaduría ${ }^{22}$. Los «dubios» del Gobernador fueron cuatro, y volvieron a plantear el mismo asunto de que se autorizara a los propietarios de esclavos de mal comportamiento a elevar su precio con el valor de la alcabala, como castigo a su mal proceder, lo que parecía justo, en vez de tener que hacerlo por el valor inicial o menor (en caso de ser coartados), aceptándose en cambio la norma de no gravar dicho importe cuando los vendieran por su propio interés ${ }^{23}$. La Corona se negó a cambiar la normativa que siguió inalterable.

21 A.G.I., Santo Domingo, 891, flo. 414v; KONETZKE [12], vol. III, t. I, pp. 360-361.

22 Este Reglamento constaba de 8 disposiciones fundamentales, que eran las siguientes:

10. Que cualquier esclavo podía comprar su libertad pagando al amo el mismo precio que pagó cuando le compró y sin necesidad de abonar ningún derecho de alcabala.

20. Que el amo que vendiera a su esclavo a otro dueño podía convenir con éste su precio, pagando el vendedor la correspondiente alcabala.

30. Que el dueño que maltratara un esclavo (comprobado por la justicia) lo vendería obligatoriamente a otro amo por el mismo precio que lo adquirió, pagando la alcabala de la venta, más «los costos y costas que se causaren»

40. Que los esclavos coartados podían comprar su libertad pagando la diferencia de precio que les faltaba (que no podía alterarse), sin abonar derechos de alcabala.

51. Que no se permitiría a un esclavo coartado pasar a otro dueño sin licencia del suyo y sin tener motivos para ello. En caso de venderse un esclavo coartado el comprador pagaría al vendedor el precio de lo entregado en coartación y el derecho de alcabala correspondiente a la tasa del esclavo.

60. Que el amo podía vender, si le conviniera, un esclavo coartado, pero sin poder alterar el precio de la coartación y pagando por ésta la alcabala.

71. Que los amos podían vender los esclavos coartados viciosos aumentando a la cantidad coartada el valor del derecho de alcabala «a justa tasación», como castigo, para dificultar su hipotética libertad futura.

81. Que cuando un amo tuviera que vender un esclavo coartado por haberle dado malos tratos, tendría que respetar el valor de la coartación y pagaría además la alcabala correspondiente al valor en que se tasara al esclavo, como castigo a su falta de humanidad.

23 Bibl. Nal., Mss. de América, 19697 (38).

R. I., $1999, \mathrm{n}^{\circ} 216$ 


\section{ALCABALAS Y COARTACIONES EN BUENOS AIRES Y SANTO DOMINGO}

Los problemas que relacionaban el pago de la alcabala y la coartación no fueron privativos de Cuba, pues también aparecieron en otros territorios como el ríoplantense o el dominicano.

En Buenos Aires los esclavos se vendían por medio de «esquelas simples», sin formalizarse debidamente, lo que ahorraba gastos inútiles a los compradores y les permitía eludir el derecho de alcabala. La situación fue tan grave que el Visitador e Intendente de Buenos Aires dio una circular el 22 de julio de 1779 ordenando a los oficiales reales que quienes compraran esclavos sin pagar la alcabala perderían su propiedad y pagarían una multa por valor de cuatro veces el valor del esclavo, quedando además este último libre (era el premio que se le otorgaba por denunciar el fraude). El Gobernador de Buenos Aires Manuel Ignacio Fernández ratificó la orden del Sr. Visitador el 25 de octubre de $1779^{24}$.

En Santo Domingo trató de regularse la coartación en el Código Negro Carolino (1783) como un premio para el buen comportamiento de los esclavos. Para dificultar las manumisiones por coartación se prohibió por la ley 60 del capítulo 19 que ningún esclavo pudiera pagar a su amo más de la mitad o dos terceras partes de su valor: «prohibimos que pueda admitírseles oblación alguna que exceda de la mitad o dos tercias partes de su valor, siendo el esclavo de buena conducta y procederes». El Código pretendió además que los esclavos informasen anualmente de sus peculios a sus dueños, a los Alcaldes de Hermandad, y a los Celadores. Incluso se retomó el asunto de gravar el precio del esclavo que tuviera mal comportamiento con el valor de la alcabala. La ley 80 del capítulo. 22 determinó que si bien se respetaría el valor del esclavo por el precio coartado «podrá acrecer a su valor el importe de la escritura y alcabala, si con su mal proceder diere lugar a su enajenación igualmente que al expresado en el Reglamento anterior, para que sirva de freno a sus menores ${ }^{25}$. Afortunadamente el Código Negro Carolino no fue aprobado y todo siguió como estaba.

\section{EL IMPERATIVO DE LO UTIL SOBRE LO JUSTO: LA COARTACION DE LA MADRE NO AFECTA AL HIJO}

En espera de que se solucionara definitivamente el problema de las coartaciones el Gobernador de Cuba don José de Ezpeleta dio un auto provisional, de acuerdo con el Auditor de Guerra de La Habana, y lo remitió al monarca con su carta al Ministro de Indias del 25 de junio de 1785, exponiendo la ambigüedad con que los abogados entendían la incidencia de la coartación de la madre escla-

\footnotetext{
24 Real Academia de la Historia, Colec. Mata Linares, t. CVIII, flos. 215-216v.

25 A.G.I., Santo Domingo, 1034.
} 
va en su hijo. Muchos de ellos entendían que tal coartación de la madre, realizada por sí misma o por sus dueños (esto último abre una vía de investigación muy poco conocida $^{26}$ ) repercutía directa y proporcionalmente en el valor de sus hijos, por lo que a veces resultaba que los hijos «después de coartados, solían valer mucho más que la madre antes de serlo». La mayor parte de los letrados opinaba, sin embargo, que el valor del hijo se rebajaba en la misma cantidad de lo que se había coartado su madre, siendo la diferencia su verdadero valor. Ezpeleta se inclinó por esto último y el auto antes citado del 7 de junio de 1786 señaló que como el hijo seguía siempre la condición de la madre, estaba afectado por la coartación que ella hubiera efectuado. Había así que establecer el valor de la esclava, descontando lo coartado. Luego había que hacer lo mismo con el hijo; tasarlo por peritos y rebajar de su precio la parte proporcional de lo que la madre había dado para su coartación. La diferencia era su justo precio a efectos de su venta, lo que parecía estar en conformidad con lo establecido en las cédulas de 21 de junio de 1768, 27 de septiembre de 1769 y 8 de abril de 1778, y con el principio lógico de que el valor de dicho hijo aumentaría luego con el tiempo, a causa de su «edad, alimento y enseñanza», no pudiendo ser fijo o inalterable. Debía tasarse entonces, pues valor no venía dado, a efectos de su libertad, por lo que su madre había coartado.

El Marqués de Sonora remitió dicha carta al Consejo de Indias con oficio 19 de septiembre de 1786, ordenando que, unida con el expediente donde se encontraban los antecedentes del asunto, se determinase una normativa general ${ }^{27}$. El Consejo tuvo que volver a estudiar el problema, requiriendo informe de la Contaduría General.

La Contaduría consideró en su informe de 16 de marzo de 1787 «justa su declaración a favor de los hijos esclavos de madres coartadas, porque así como por el derecho se les obliga al duro y penoso yugo de la esclavitud por haber nacido de madre esclava, parecía por congruencia de razón deber disfrutar y ser participantes de cualquiera beneficio que resultase a favor de ella». También informó el Fiscal don Antonio Porlier, mediante una representación del 30 de marzo de 1787, en la que ponderó los principios de derecho y equidad que guiaban la representación de Ezpeleta, llegando a afirmar «que si el hijo de la esclava se reputaba por tal, a causa de deber seguir siempre la condición de la madre, no podía haber sólida razón para que se le denegase la participación de aquel beneficio que estaba disfrutando la madre cuando le procreó mediante la coartación referida». Consideró por tanto justo que el precio del hijo fuera la diferencia entre su valor total y la cantidad en que la madre había estado coartada.

\footnotetext{
26 ¿Les otorgaban premios a sus esclavos, que anotaban como coartaciones?

27 La resolución del Consejo de Indias sobre que la coartación de la madre no afecta al hijo, citada anteriormente.
}

R. I., 1999, n. ${ }^{\circ} 216$ 
Sin embargo, la segunda parte de la representación de Porlier contradijo todo lo que había dicho en la primera, sacrificando la razón a la conveniencia. Tras su veredicto «legal» añadió que no podía perderse de vista el hecho de que los esclavos eran necesarios para la agricultura indiana, particularmente en Cuba, y que los esclavos manumitidos no podían ser obligados a trabajar, motivo por el cual muchos de ellos se entregaban a la holgazanería. Teniendo así en cuenta «los inconvenientes políticos que se seguían de facilitar demasiado aquel beneficio (la libertad) en unas partes donde necesariamente eran indispensables los esclavos para el cultivo de la tierra y aprovechamiento de sus frutos y producciones», así como el hecho de que el deseo de adquirir lo necesario para la coartación inducía a las esclavas a conseguirlos muchas veces por medios ilícitos y deshonestos, «con conocido daño de las conciencias de las mismas esclavas y de sus cómplices en el pecado», se inclinaba por prohibir dicha coartación o interponer al menos «algunas limitaciones adecuadas a superar en el modo posible los inconvenientes indicados, sin perjuicio de la libertad y de lo favorable de ella», remitiendo la resolución del problema al monarca, a quien se le pondría en antecedentes de los inconvenientes «políticos y aún morales a que daba margen la permisión de poderse coartar las esclavas». Resulta curioso este enfrentamiento entre lo «razonable» y lo «útil» en el pensamiento de un ilustrado (Porlier era uno de sus mejores exponentes) y mucho más que valorara lo conveniente sobre lo justo, pero seguramente fue compartido por otros muchos ilustrados españoles, llenos de contradicciones sobre el valor de la diosa «razón».

El Consejo revisó el expediente en su sala primera el 19 de abril de 1787 y decidió trasladarlo al pleno de las dos salas, acompañando un ejemplar de la Real Cédula de 12 de abril de 1786 sobre el fomento de la agricultura en la colonia de Santo Domingo (obra de Emparan ${ }^{28}$, autor del Código Negro Carolino). Allí se vio el asunto y se remitió nuevamente a los dos Fiscales, con cuyo veredicto se pasó al pleno de las tres salas, precediendo consulta con el Rey el 16 de junio del mismo año.

El pleno de las tres salas dio finalmente su veredicto, que fue el de revocar el auto dado por Ezpeleta «como opuesto a derecho, pues la coartación en las madres es sólo para ellas tan personal que no puede ser transmisible a los hijos a fin de que estos logren del mismo beneficio, para que sean vendidos en menos valor de el que en realidad tienen. Que el que nace esclavo, aunque sea de madre coartada, no por esta calidad debe carecer de cuantos efectos causa la esclavitud en cuanto al absoluto dominio que deben tener los dueños y señores sobre ellos». Se añadieron algunas otras consideraciones - prueba evidente de la falta de razóncomo el peligro que representaba extender al resto de Hispanoamérica esta nor-

28 Vide sobre esta obra y Emparan Manuel LuCENA SALMORAL, Los Códigos Negros de la América Española, Alcalá de Henares, Colección Memoria de los Pueblos, Ediciones UNESCO 96, UNESCO/UNIVERSIDAD DE ALCALÁ, 1996. 
mativa particular de Cuba, la merma que la baja de alcabala representaría de disminución para la Real Hacienda, y los argumentos «políticos» que había aducido Porlier: el peligro de que los esclavos acudieran a procedimientos ilícitos para procurarse el dinero y el de que los hijos fueran «unos públicos haraganes en la sociedad, como lo experimenta con los más que consiguen la libertad, y se aminorarían los trabajadores, tan necesarios en aquellas preciosas poblaciones». Esta resolución del Consejo se dio el 5 de diciembre de $1788^{29}$. El 10 de febrero de 1789 se dio una real cédula con la normativa a seguir: «la coartación de las madres es sólo para ellas, tan personal que no puede ser transmisible a los hijos, a fin de que éstos logren el mismo beneficio, para que sean vendidos en menos valor del que en realidad tienen ${ }^{30}$.

La coyuntura resulta interesante, pues 18 días después, el 28 de febrero de 1789 se dio la libertad de trata de esclavos para las Antillas y Caracas $^{31}$, y tres meses después, el 31 de mayo de 1789 se dio la cédula real con la Instrucción para la Educación, trato y ocupaciones de los esclavos, que había hecho rápidamente don Antonio Porlier ${ }^{32}$.

\section{SUPRESION DE LA ALCABALA PARA LAS MANUMISIONES}

Aunque en la normativa enviada al Gobernador de Cuba el 21 de junio de 1768 y había quedado claro que el esclavo que se ahorraba quedaba exento de pagar dicho impuesto, no se había determinado qué ocurría en el caso de que el amo otorgase generosamente la libertad a su esclavo, cosa que planteó problemas al alcalde de Lorica, una localidad del Nuevo Reino de Granada. Pidió aclaración al Gobernador de Cartagena y éste remitió la consulta al Virrey de Santa Fe, quien decidió escribir al monarca el 28 de febrero de 1789 pidiendo resolución sobre la duda planteada. El monarca le contestó mediante real cédula de 27 de octubre de 1790 señalando que ninguno de los funcionarios debía haber dudado

\footnotetext{
29 A.G.I., Audiencia de Santo Domingo, 1142; KoneTZKe [12], vol.III, t. II, pp. 631-635.

30 Abelardo LeVAGGI, «Condición jurídica del esclavo en la época Hispana», Revista de Historia del Derecho, 1, Buenos Aires, Instituto de Investigaciones de Historia del Derecho, 1973, p. 122.

31 Brit. Libr., Egerton Mss. 520. Papeles sobre las colonias de España, flo. 257-263; PICHARDO [3], t. I, pp. 158-161.

32 Instrucción para la educación, trato y ocupaciones de los esclavos, dada en Aranjuez el 31 de mayo de 1789. Bibl. Nal., Mss. de América, 8734, flo. 1-8v. También A.G.I., Indiferente, 802; A.H.N., Diversos, Reales Cédulas, núm. 898; Konetzke, vol. III, segundo t., pp. 643-652. Vide Manuel LUCENA SALMORAL, «La Instrucción sobre Educación, trato y ocupaciones de los esclavos de 1789; una prueba del poder de los amos de esclavos frente a la debilidad de la Corona española», Estudios de Historia Social y Económica de América, núm. 13, Alcalá de Henares, 1996, pp. 155-178; y «El original de la R.C. Instrucción circular sobre la Educación, trato y ocupaciones de los esclavos en todos sus dominios de Indias e Islas Filipinas», Estudios de Historia Social y Económica de América, núm. 13, Alcalá de Henares, 1996, pp. 311-317.
} 
sobre la obligación de pagar la alcabala «pues interviniendo un verdadero contrato de compra y venta entre el señor que vende la libertad del esclavo y éste que la compra, se debía exigir la alcabala del vendedor», pero que siendo necesario dictar una norma general, y dada la intención de favorecer la libertad del esclavo (siendo necesario evitar estorbos por parte de los amos, que cargarían a los esclavos dicha alcabala), se había decidido, tras consultar al Consejo de Indias y estudiar un informe del Contador General, en conformidad con cédulas anteriores «he resuelto, declarando no debe exigirse el referido derecho de alcabala del contrato que se celebra entre el señor y el esclavo, cuando éste se redime por precio adquirido lícitamente, y lo mismo cuando por pura liberalidad de su dueño obtiene la libertad», lo que se daba como norma general para las Indias y Filipinas. Se suprimió así dicha alcabala en casos de manumisión, tanto si ésta era conseguida mediante compra del propio esclavo (bien mediante coartación o pago total del precio), como si lo era por generosidad del amo ${ }^{33}$.

\section{LA COARTACION EN EL SIGLO XIX}

Lo reglamentado sobre las coartaciones en la segunda mitad del siglo XVIII se mantuvo vigente en Cuba y Puerto Rico durante la centuria siguiente. Así lo recogió por ejemplo el Reglamento de Esclavos de Puerto Rico dado el 12 de agosto de 1826:

11.- No podía subirse el precio de los esclavos coartados. Su artículo 21 del capítulo X señaló: «Cuando los amos vendan sus esclavos por conveniencia o voluntad propia tendrán la libertad de venderlos (si no estuvieren coartados) por el precio en que convinieren los compradores, según la mayor o menor estimación que tuvieren». Y el artículo 41 del mismo capítulo anotó: «Los esclavos coartados no se pueden vender en más precio que el que se fijó al tiempo de la coartación, pagándose únicamente el del resto de ella, pasando con este mismo gravamen al comprador».

21.- Los hijos de madres coartadas no gozaban del beneficio de la coartación de aquellas, por considerarse la coartación personal e intransmisible, como se recordó en el artículo 51: «Los hijos de madres coartadas no gozan del beneficio de la coartación de aquéllas, por ser personalísimo e intransmisible, y pueden ser vendidos por todo el valor en que convenga el amo con el comprador, o en el que le den peritos y tercero en discordia,

33 Roberto Arrazola, Palenque, primer pueblo libre de América, Cartagena, Cartagena, Ediciones Hernández, 1970, pp. 289-290; Cedulario de la Real Audiencia de Buenos Aires, La Plata, Advertencia de Ricardo Levenne, 1929, vol. I, núm. 1 174, pp. 421-422. 
según los casos, y en los mismos términos expresados en los artículos 31 y 41 de este capítulo» ${ }^{34}$.

En el Reglamento de esclavos de Cuba del 14 de noviembre de 1842 se recogió igualmente en el artículo 36 la norma de que los hijos de las madres coartadas no gozarían del beneficio de la coartación y se venderían como cualquier otro esclavo: «Siendo el beneficio de la coartación personalísimo, no gozarán de él los hijos de madres coartadas, y así podrán ser vendidos como los otros esclavos enteros». Algo muy interesante fue estipular una cantidad fija (aproximadamente la sexta parte del valor usual) para que el amo estuviera obligado a aceptar la coartación. El artículo 34 determinó que ningún amo podía negarse a coartar al esclavo que le ofreciera al menos 50 pesos: «Ningún amo podrá resistirse a coartar sus esclavos, siempre que se le exhiban al menos cincuenta pesos a cuenta de su precio». También se incluyó en el mismo norma de que ningún amo vendiese su esclavo por mayor valor del que se hubiera establecido en la ultima coartación (artículo 35), pero añadió que los esclavos que tuvieran mal comportamiento pagarían el valor de la alcabala para ahorrarse, a modo de castigo: «si el esclavo quisiera ser vendido contra la voluntad de su amo, sin justo motivo para ello, o diere margen con su mal proceder a la enajenación, podrá el amo aumentar al precio de la coartación el importe de la alcabala y los derechos de la escritura que causare su venta» ${ }^{35}$.

Una novedad de esta centuria fue la incidencia de las coartaciones en los salarios que los esclavos jornaleros debían entregar a sus amos. Estaban regulados en tres reales por día laborable, pero el artículo 21 de la Circular del Gobernador de Puerto Rico del 5 de mayo de 1849 estableció: «A los esclavos coartados sólo se exigirá un real por cada cien pesos de su valor, en el primer caso, y tres cuartos de real, en el segundo (si se les diera manutención y vestuario)» ${ }^{36}$, lo que se rati-

\footnotetext{
34 Reglamento sobre la educación, trato y ocupaciones que deben dar a sus esclavos los dueños y mayordomos de esta Isla. San Juan de Puerto Rico, 12 de agosto de 1826. Francisco RAMOS, Prontuario de Disposiciones Oficiales de Puerto Rico, San Juan, Imprenta González, 1866, pp. 164-168; Joaquín RODRIGUEZ SAN PEDRO, Legislación Ultramarina, concordada y anotada por..., con la colaboración de D. Antonio Fernández Chorot, D. Eduardo y D. Arturo Piera y D. Manuel González Junguitu, Madrid, Imp. de los señores Viota, Cubas y Vicente, 1865-1869, t. II, pp. 587-593; El proceso abolicionista, t. II, pp. 103-112. Vide Manuel LUCENA SALMORAL, «El «Código negro» de Puerto Rico, 1826», Boletín de la Academia Puertorriqueña de la Historia, núms. 45-48, San Juan de Puerto Rico, 1993 [publicado en 1996], pp. 83-119.

35 PICHARDO [3]. t. I, p. 318-326; Legislación Ultramarina, t. II, pp. 545-568; José María ZAMORA Y CORONADO, Biblioteca de Legislación Ultramarina, Madrid, imprenta de Alegría y Charlain, 1844-1846, t. 3, p. 136-139; PÉREZ-CiSNEROS, [3], pp. 87-98. Vide Manuel LuCENA SALMORAL, «El Reglamento de esclavos de Cuba», Revista del Caribe, núm. 25, Santiago de Cuba, 1996, pp. 89-99.

36 Legislación Ultramarina, t. II, p. 596.
} 
ficó en el Bando de Policía del 15 de diciembre de 1849 para la misma isla ${ }^{37}$. Esto quería decir que el esclavo podía quedarse con la diferencia del salario, lo que en definitiva le permitiría acelerar su coartación y manumisión definitiva.

También se les otorgaron facilidades en Cuba, pues el Reglamento para las sindicaturas de La Habana, hecho el 28 de enero de 1863, estableció que los amos que tuvieran a su servicio esclavos coartados debían pagarles la diferencia existente entre el jornal que pudieran obtener trabajando por su cuenta y el que les correspondiera satisfacer: "Artículo 11. Los amos de esclavos coartados que los tengan a su servicio les deben la diferencia entre el jornal que les corresponda satisfacer y el que ellos pudieran obtener trabajando por su cuenta, lo cual no excluye el acuerdo entre dueño y esclavo sobre el particular» ${ }^{38}$.

El derecho de coartación se mantuvo hasta fines de la esclavitud. En el proyecto de ley de su abolición, aprobado por las Cortes en diciembre de 1879, y sancionado por Alfonso XII el 13 de febrero de 1880 como ley para la supresión de la esclavitud en $\mathrm{Cuba}^{39}$ se anotó: "Artículo 11. Los individuos coartados al promulgarse esta ley conservarían en su nuevo estado de patrocinados los derechos adquiridos por la coartación. Podrán además utilizar el beneficio consignado en el caso cuarto del art. 71, entregando a sus patronos la diferencia que resultara entre la cantidad que tuvieren dada y la que corresponda por indemnización de servicios, con arreglo a lo dispuesto en el artículo y caso mencionados» ${ }^{40}$. Los beneficios de la coartación se reconocieron incluso en el Reglamento para la ejecución de la ley del Patronato de Cuba de 8 de mayo de 1880, pues su artículo 57 determinó: «Los patrocinados procedentes de la clase de esclavos coartados conservarán los derechos que de la coartación derivaban, con sujeción a las disposiciones de la ley de 13 de Febrero» ${ }^{41}$.

La coartación fue así un derecho consuetudinario que funcionó en Hispanoamérica durante la segunda mitad del siglo XVIII, cuando tuvo que regularse por haber incidido en el problema del pago de alcabala por la venta de esclavos. Llegó a ser obligatoria para los amos a los que los esclavos les entregaban al menos una cantidad equivalente a la sexta parte de su valor y fue un derecho personal, que la madre esclava no podía transferir a su hijo. La coartación fijaba además del precio del esclavo, que el amo no podía subir a su antojo. En caso de venderse un esclavo coartado se traspasaba al nuevo amo con el mismo valor de lo coartado, teniendo que pagar el comprador la diferencia entre el precio del siervo y lo que hubiera coartado. La Corona eximió del pago de alcabala las manumi-

\footnotetext{
37 Bando de Policía de Puerto Rico; Legislación Ultramarina, p. 418.

38 Legislación Ultramarina, t. II, p. 572.

39 Ley de supresión de la esclavitud y del Patronato, Madrid, 13 de febrero de 1880, ya citada en Gaceta de Madrid, 18 de febrero de 1880.

40 Gaceta de Madrid, 18 de febrero de 1880; PÉreZ-Cisneros [3], pp. 137-143; PiCHARdo [3], t. I, p. 414-418

41 A.H.N., Ultramar, 4926; C. NAVARRo AZCUE [3], pp. 285-288.
} 
siones efectuadas por el esclavo que compraba su libertad (mediante coartación o pago completo) o la adquiría por generosidad del amo, pero en casos de mal comportamiento del esclavo (cuando su amo estaba obligado a venderlo) se permitió aumentar al precio del siervo el valor de la alcabala, a modo de castigo. La coartación finalmente incidió en rebajar los salarios que los amos cobraban a sus esclavos jornaleros, lo que les permitía aumentar el peculio y la posibilidad de ahorrarse más pronto. La coartación fue sin duda el mejor y mayor mecanismo de liberación de los esclavos en la América española y permitió la aparición de una importante población libre, que la diferenció de otras colonias americanas.

Coartación is the right of the slave to buy his freedom by paying his master a given price through a system of periodic instalments. It was a matter of common law in Colonial Spanish America which, by generating the greatest number of liberations, gave way to the formation of a free population of black people which was characteristical of these colonies. It worked from mid 18th Century to abolition, and generated a series of legal problems with regard the possible sale of that slave to another master due to the payment of alcabala (i.e., whether it should be payed from the part subject to coartación), as well as in cases such as the son of a coartada mother, since he inherited the slave condition from his mother, who was free only in part. This article deals with the solutions given to these problems.

R. I., $1999, \mathrm{n}^{\circ} 216$ 